\title{
EDITORIAL
}

\section{Healthy people, healthy journal}

\author{
Sai-Juan CHEN ${ }^{1}$, Xiao-Ping CHEN ${ }^{2}$, Guang-Biao ZHOU $^{3}$ \\ 1 Shanghai Insitute of Hematology, Rui-Jin Hospital Affiliated with Shanghai Jiao Tong University School of Medicine, Shanghai, China \\ 2 Tongji Hospital, Tongji Medical College, Huazhong University of Science and Technology, Wuhan, China \\ 3 Institute of Zoology, Chinese Academy of Sciences, Beijing, China
}

(C) Higher Education Press and Springer-Verlag Berlin Heidelberg 2010

Birth-to-death, with disease shares the contours. That is everyone's destiny.

But in health we care, we struggle for healthier life, better medicine, and dignified survival. The past six decades have witnessed China's tremendous advances in the development of living condition and health-care system. The life expectancy of Chinese people increased from 36.5 years in 1949 to 73 years in 2005, and will reach 85 years by 2050. The infant mortality rate decreased from 200 per 1000 in 1949 to 14.9 per 1000 in 2008. While other countries are suffering and recovering from the financial crisis, China has passed the long-awaited health reform plan which will provide citizens with improved health care service, reduced economic burdens, and extended health coverage.

However, China, home to 1.3 billion people (accounting for one fifth of the world's population), is still a developing country. Infectious diseases remain public health threats to Chinese people. For example, China has 4.5 million tuberculosis cases with 160000 people succumbed to this disease in 2008. More than 100 million people are infected with hepatitis B virus, and 300000 people die of hepatitis $B$ virus-related diseases every year. There are currently an estimated 840000 people living with human immunodeficiency virus, including about 80000 patients with acquired immune deficiency syndrome (AIDS). On the other hand, around 260 million Chinese, or about $20 \%$ of the population, are suffering from chronic diseases including hypertension and diabetes. Cancer is now the No. 1 killer in cities and No. 2 in the countryside, causing more than 1.6 million deaths each year. These data elucidate that the health care system as well as families in China is facing great challenges in fighting diseases. Moreover, though more and more people flock into metropolis such as Beijing and Shanghai, 900 million residents still live in rural areas, with about 100 million in impoverished and remote areas that are reminiscent of the world's most forgotten regions. Providing healthcare in these regions is an extremely difficult task.

China has launched the reform with an investment plan of CNY 850 billion (124 billion USD) on improving medical and health care system to achieve universal access to basic medical and health services for all of its citizens. While applauding the efforts of medical and health sectors to provide better medical care to everyone, the Frontiers of

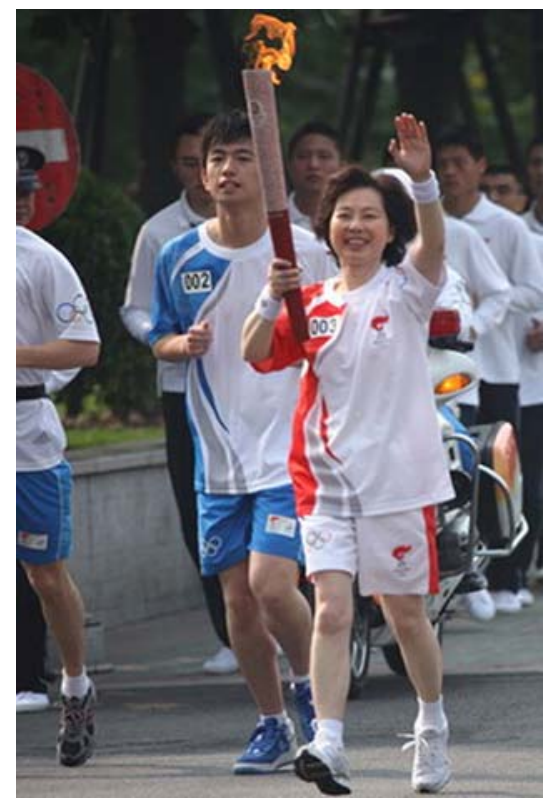

Fig. 1 Dr. Sai-Juan CHEN in Torch Relay, 2008 Olympic Game, Beijing, China

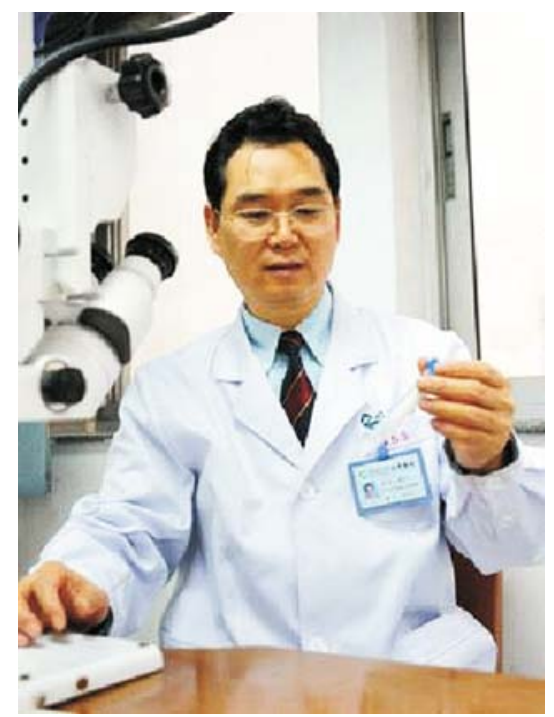

Fig. 2 Dr. Xiao-Ping CHEN working in his laboratory, Wuhan, China 
Medicine in China is determined to play its role in accelerating the pace by turning knowledge into action and translating science into practice. The Frontiers of Medicine in China will report the advances in medicine and news from the front of war against diseases. Statistics in medicine will be documented, clinical therapeutics and public health interventions with novelty will be demonstrated, and excellent research articles, particularly those with crossdisciplinary approach, will be published. Medical science does not have a border, and Frontiers of Medicine in China bears a global vision through which it cares medicine and humanity in other nations/regions especially the developing countries.

"Are medical journals getting better - or worse?" The Lancet asked in Sep. 2009. Interestingly, PLoS Medicine announced its prescription for a healthy journal in Oct. 2004. The Frontiers of Medicine in China, however, will try to promote health and help control disease by showing the facts in medicine and sharing experience in disease control and treatment, through fair peer review process. We strive for reaching the convergence of innovation, effectiveness, and scientific integrity.

"Healthy people, healthy journal" is our aim. We welcome every individual's efforts for promoting health and preventing/curing disease, and welcome every support including submission and comment from home and abroad to the Frontiers of Medicine in China.

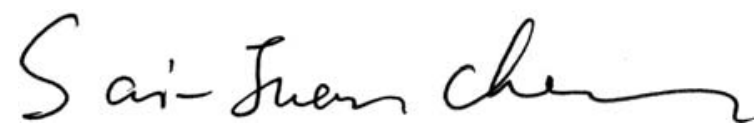

Sai-Juan CHEN, Editor-in-Chief

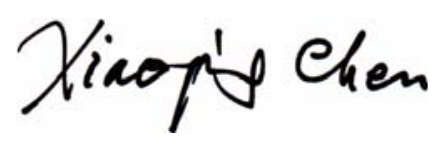

Xiao-Ping CHEN, Editor-in-Chief

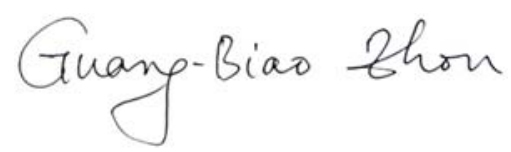

Guang-Biao ZHOU, Executive Deputy Editor-in-Chief 